\title{
Maternally expressed 3 inhibits the biological activity of oral squamous cell carcinoma SCC25 and CAL27 cell lines
}

\author{
WENJING WANG ${ }^{1}$, HUANJU LI ${ }^{2}$, YONGLE QIU ${ }^{1}$, KUNSHAN LI ${ }^{1}$, \\ YUETING LU ${ }^{1}$, QIANLAN DENG ${ }^{1}$ and TIEJUN LIU ${ }^{1}$ \\ ${ }^{1}$ Department of Stomatology, Fourth Affiliated Hospital, Hebei Medical University, Shijiazhuang, Hebei 050000; \\ ${ }^{2}$ Department of Surgery, Gucheng County Hospital, Hengshui, Hebei 253800, P.R. China
}

Received February 2, 2021; Accepted July 28, 2021

DOI: $10.3892 / 01.2021 .13045$

\begin{abstract}
The abnormal expression of long non-coding RNA (lncRNA) maternally expressed 3 (MEG3) is closely related to several tumor diagnosis and progression, such as endometrial carcinoma and ovarian cancer. However, the role of MEG3 in oral squamous cell carcinoma (OSCC) is rarely reported. The current study aimed to evaluate the expression of lncRNA MEG3 in OSCC tissues and cell lines and its effect on the biological behavior of OSCC cell lines. The expression of IncRNA MEG3 in the OSCC tissues and cell lines was detected by reverse transcription-quantitative (RT-q) PCR. The relationship between MEG3 expression and the clinicopathologic characteristics and prognosis of patients with OSCC was analyzed. The lncRNA MEG3 overexpression plasmid and control plasmid were transfected into SCC25 and CAL27 cell lines using the lipofectin method. MTT assay was performed to detect the growth and proliferation of the cell lines. Transwell chamber test was used to detect changes in cell migration and invasion. Flow cytometry was employed to detect changes in apoptosis. Western blotting and RT-qPCR were conducted to detect the expression of the p53 gene. The expression of IncRNA MEG3 in the OSCC tissues and cell lines was significantly compared with normal tissues and cell lines, respectively. The expression level of MEG3 was related to clinical stage, lymph node metastasis, distant metastasis and survival status. Overexpression of lncRNA MEG3 inhibited the proliferation, migration, and invasion of SCC25 and CAL27 cell lines, induced apoptosis and promoted the expression of p53 gene. 1ncRNA MEG3 played the role of a tumor inhibitor gene and significantly inhibited the biological activity of OSCC cell lines, which may provide a novel idea for molecular targeted therapy of OSCC.
\end{abstract}

Correspondence to: Professor Tiejun Liu, Department of Stomatology, Fourth Affiliated Hospital, Hebei Medical University, 12 Health Road, Shijiazhuang, Hebei 050000, P.R. China

E-mail: liutiejun19730427@163.com

Key words: oral squamous cell carcinoma, long non-coding RNA, maternal expression gene 3

\section{Introduction}

Oral squamous cell carcinoma (OSCC) has the biological characteristics of uncontrollable invasiveness, high mortality and extensive hypoxia (1). Data from the Surveillance, Epidemiology, and End Results in 2000 suggested that 28,900 people in the US are diagnosed with OSCC every year, of which $\sim 7,400$ deaths are reported annually (2). Although the comprehensive sequence therapy of this cancer has achieved outstanding results, the quality of life of patients with advanced stage OSCC is still very poor $(3,4)$. Hence, the in depth study of the mechanism of OSCC is crucial for the selection of appropriate tumor markers and the discovery of new therapeutic strategies. Previous studies have focused on OSCC protein-coding genes $(5,6)$. Recent studies have shown that lncRNA may serve an important role in the pathogenesis of OSCC (7-9).

Most lncRNAs were initially considered as nonfunctional 'noise', by-products of RNA polymerase II transcription and without biological function (10). However, lncRNA had been found to be involved in $\mathrm{X}$ chromosome silencing, genomic imprinting, gene modification, transcriptional activation, transcriptional interference, and nuclear transport (11-13). Hence, the role of lncRNAs has gradually attracted extensive attention. With extensive studies in recent years, IncRNAs have been demonstrated to regulate gene expression at the epigenetic, transcriptional and posttranscriptional levels, which is more direct and rapid in regulating cell proliferation, migration and differentiation $(14,15)$. A previous study demonstrated that lncRNA is involved in diverse pathological processes of tumorigenesis and development at different levels (16). In addition, IncRNA has been demonstrated to participate in a number of important physiological and pathological processes, such as cell proliferation (17), differentiation (18), tissue formation (19) and organ formation (20).

The abnormal expression of lncRNA had been reported in the first-generation map in 2011, which involved as many as 19 kinds of cancer (21). The lncRNA can act as a regulator of gene expression through gene modification, transcription and postprocessing (22). In the past few years, numerous studies have shown that the upregulation and downregulation of lncRNA are involved in the development and progress of OSCC $(23,24)$. High expression of some lncRNAs in OSCC 
(such as lncRNA PDIA3P, lncRNA FGD5-AS1 and lncRNA HOXA11-AS) can promote the proliferation, invasion, and migration of cancer cells (25-27).

LncRNA MEG3 is located on the human chromosome $14 \mathrm{q} 32.3$, with a length of $\sim 1600$ nucleotides (28). This transcript consists of 10 exons and is expressed in maternal alleles (29). In 1998, Schuster Gossler and his colleagues found MEG3 was highly expressed in the paraxial mesoderm of mouse embryos, suggesting it may be involved in regulating the process of myogenesis (30). Subsequently, Takahashi et al and Zhou et al found the developmental defect of skeletal muscle and perinatal death in MEG3 knockout mice, indicating that MEG3 may serve an instrumental role in the regulation of embryo formation and skeletal muscle development $(31,32)$. In addition, MEG3 also functions by regulating the differentiation of mouse embryonic stem cells by promoting the interaction between the accessory component of Polycomb repressive complex-2 JARID2 with its' core component EZH2 $(33,34)$. Recent research has revealed that lncRNA MEG3 is expressed in normal human tissues and lowly expressed in gastric cancer, breast cancer, etc. $(35,36)$. However, its expression in OSCC is rarely reported. The present study aimed to investigate the effects of lncRNA MEG3 on the proliferation, migration and p53 pathway of SCC25 and CAL27 OSCC cells. IncRNA MEG3 may be a therapeutic target for patients with OSCC.

\section{Materials and methods}

Participants. The OSCC tissues and corresponding normal tissues ( $>2 \mathrm{~cm}$ from the edge of the tumor) were collected from 72 patients who underwent surgical resection in the Department of Stomatology, the Fourth Affiliated Hospital of Hebei Medical University between January 2015 and December 2016. The patients had complete data and definite diagnosis by pathological examination and were all first episode patients. The subjects had no treatment for OSCC before the operation and signed written informed consent. The samples were collected from 35 males and 37 females with a mean age of 53 years (range, 21-75 years). The Ethics Committee of the Fourth Affiliated Hospital (Shijiazhuang, China) approved the experiment and supervised and guided the whole experimental process (approval no. 201411EC040). All patients were followed up immediately after discharge. By 31 st December 2019, 49 cases survived and 23 cases succumbed to the disease.

Materials and reagents. The following materials were used to investigate the expression of the $p 53$ gene: primers of MEG3, p53, pcDNA3.1-MEG3 overexpression plasmids and an empty control plasmid (Wanleibio Co., Ltd.). The normal oral mucosa cell line (hNOK) and OSCC cell line SCC25 and CAL27 were purchased from BeNa Culture Collection; Beijing Beina Chunglian Institute of Biotechnology). Dulbecco's Modified Eagle's Medium (DMEM) and fetal bovine serum (FBS) were purchased from Gibco; Thermo Fisher Scientific, Inc. BSA, DMSO and MTT reagent were purchased from Sigma-Aldrich; The expression of the $p 53$ gene was detected using TRIzol ${ }^{\circledR}$ RNA isolation kit, Lipofectamine ${ }^{\circledR} 2000$ liposome, Matrigel, Invitrogen Superscript Reverse Transcriptase kit and SYBR Green qPCR Master Mix kit which were all purchased from
Invitrogen (Thermo Fisher Scientific, Inc.). Rabbit anti-human monoclonal and goat anti-rabbit secondary antibodies were purchased from Santa Cruz Biotechnology Co., Ltd.

Reverse transcription-quantitative ( $R T-q) P C R$ experiment. The total RNA was extracted from the appropriate tissues using TRIzol for RNA quality inspection, and cDNA was prepared via reverse transcription. Fluorescence quantitative analysis was performed according to the operational instructions of the SYBR Green qPCR Master Mix kit. According to the target sequence, the corresponding upstream and downstream primers were designed and synthesized for PCR amplification. GAPDH was used as internal reference gene. The primer sequences were as follows: IncRNA MEG3 forward, 5'-CTTTTCTGGGGGAATGGGG-3' and reverse, 5'-AGAGGGGTGGGAAGGGACT-3'; p53 forward, 5'-ACC ACCATCCACTACAACTACAT-3' and reverse, 5'-CAGGAC AGGCACAAACACG-3'; and GADPH forward 5'-CTTAGT TGCGTTACACCCTTTCTTG-3' and reverse, 5'-CTGTCA CCTTCACCGTTCCAGTTT-3'. The thermocycling conditions were as follows: pre-denaturation at $95^{\circ} \mathrm{C}$ for $10 \mathrm{~min}$, denaturation at $95^{\circ} \mathrm{C}$ for $15 \mathrm{sec}$, annealing at $60^{\circ} \mathrm{C}$ for $30 \mathrm{sec}$, elongation at $72^{\circ} \mathrm{C}$ for $30 \mathrm{sec}$ and final extension at $72^{\circ} \mathrm{C}$ for $2 \mathrm{~min} 30 \mathrm{sec}$. The expression of IncRNA was calculated with GAPDH as internal reference. After three independent experiments, the data were obtained by using the following formula: $\Delta \mathrm{Cq}=\mathrm{Cq} \operatorname{lncRNA}-\mathrm{Cq} \mathrm{GAPDH}$; and $\Delta \Delta \mathrm{Cq}=(\mathrm{Cq} \operatorname{lncRNA}-\mathrm{Cq}$ GAPDH)-(Cq lncRNA-Cq GAPDH) experimental group-(Cq lncRNA-Cq GAPDH) control group. When the relative expression of OSCC and normal tissues were counted, the relative expression of each sample $\left(2^{-\Delta \Delta \mathrm{Cq}}\right)$ and the changes in the IncRNA in different tissues were compared (37).

Cell culture and plasmid transfection. The SCC25 and CAL27 cells were seeded in DMEM containing 10\% FBS and cultured in a $95 \% \mathrm{CO}_{2}$ incubator at $37^{\circ} \mathrm{C}$. The medium was changed, and subculturing was performed every 3-4 days. The cells in the logarithmic growth phase were seeded on a 6-well plate and transfected when the cells grew to $\sim 70 \%$ confluency. The PEGFP-N1 plasmid (Clontech; Takara Bio USA) transfection was performed according to the manufacturer's instructions of the Lipofectamine 2000 transfection reagent. The transfection concentration was $40 \mathrm{nmol} / 1$ at $37^{\circ} \mathrm{C}$ for $20 \mathrm{~min}$. After transfection, the cells were cultured in the incubator for $6 \mathrm{~h}$, and then the medium was replaced with DMEM containing $10 \%$ FBS. After $48 \mathrm{~h}$ of transient transfection, the RNA was extracted to test the transfection efficiency.

Experimental grouping. The experiment was divided into the following: blank control group (NC), untransfected SCC25 and CAL27 cells; vector group (empty vector), SCC25 and CAL27 cells transfected with pcDNA3.1 empty control plasmid; and overexpression group (pcDNA3.1-MEG3), SCC25 and CAL27 cells transfected with pcDNA3.1-MEG3.

MTT assay. The SCC25 and CAL27 cells were seeded on 96-well plates with $1 \times 10^{4}$ cells in each well. After the cells adhered to the wall, transfection was performed. Each group was set with 3 multiple wells. After 6, 24, 48, 72 and 96 h of culture, $10 \mu \mathrm{l}$ of MTT solution was added to each well, and the 
incubation was continued for at $37^{\circ} \mathrm{C}$ for $4 \mathrm{~h}$. DMSO was used for purple formazan dissolution. The OD value was measured at $570 \mathrm{~nm}$ by a microplate analyzer, and the cell growth curve was plotted (38).

Transwell chamber assay. For the migration experiment, the experimental groups were the same as those in section. After $48 \mathrm{~h}$, the transfected cells were collected, and the cells were suspended in serum-free medium at a density of $2.5 \times 10^{5}$ cells $/ \mathrm{ml}$. Then, 200 and $600 \mu \mathrm{l}$ of the serum-free medium were added to the upper and lower chambers of $6.5 \mathrm{~mm}$ Transwell with $8.0 \mu \mathrm{m}$ pore polycarbonate membrane insert (Corning, Inc.), respectively, which was stored at $37^{\circ} \mathrm{C}$ for $1 \mathrm{~h}$. The medium in the well was absorbed and discarded, and the chamber was washed twice with PBS. Then, $200 \mu 1$ of the cell suspension was added in the upper chamber, and $800 \mu \mathrm{l}$ of the medium containing 30\% FBS was added to the lower chamber cultured at $37^{\circ} \mathrm{C}$ for $48 \mathrm{~h}$. The Transwell chamber was cleaned with PBS, fixed with $4 \%$ paraformaldehyde at $25^{\circ} \mathrm{C}$ for $20 \mathrm{~min}$ and stained with $0.5 \%$ crystal violet for $5 \mathrm{~min}$. The cells migrated to the lower layer of the microporous membrane were counted under an inverted microscope (magnification, $\mathrm{x} 200$ ). Five visual fields/samples were counted, and the mean was determined. For the invasion assay, Matrigel gel was thawed at $4^{\circ} \mathrm{C}$ and diluted with serum-free medium at the ratio 1:3 under a clean worktable. The Transwell chambers were placed in 24-well plates coated with $40 \mu \mathrm{l}$ of Matrigel and then incubated in an incubator at $37^{\circ} \mathrm{C}$ for $2 \mathrm{~h}$. The remaining steps were the same as those listed for the migration experiment.

Flow cytometric analysis. The cells were inoculated in 6-well plates with $5 \times 10^{5}$ cells per well. After $48 \mathrm{~h}$ of transfection, the cells in each group were collected and washed twice with PBS, and $500 \mu \mathrm{l}$ of the binding buffer was added to gently suspend the cells. Annexin VLIGHT 650/PI apoptosis detection kit was purchased from Wanleibio Co., Ltd., which was used according to the manufacturer's protocols. Annexin V-light $650(5 \mu 1)$ was added, and the mixture was evenly mixed. Then, $10 \mu \mathrm{l}$ of propidium iodide was added, and the mixture was evenly mixed again. The cells were incubated at room temperature for $15 \mathrm{~min}$, and apoptosis was detected via flow cytometry (using Beckman Analysis 2.0) and analyzed using Kaluza Analysis 2.0 (Beckman Coulter, Inc.).

Western blot analysis. The protein was extracted using total protein extraction kit (Wanleibio Co., Ltd.). The protein concentrations were detected using bicinchoninic acid protein quantification kit (Wanleibio Co., Ltd.). After 48 h of transfection, the p53 protein was detected using a Bio-Rad vertical electrophoresis system. Then, $5 \%$ of concentration gel and $12 \%$ of separation gel were selected as electrophoresis plastic. Next, 5X Loading Buffer and PBS were used to dilute the protein sample, which was boiled in a water bath for $5 \mathrm{~min}$, and $20 \mu \mathrm{l}$ solution was prepared with $40 \mu \mathrm{g}$ protein loaded per lane. The proteins were transferred to PVDF blotting membrane at $80 \mathrm{~V}$ for $1.5 \mathrm{~h}$, and $5 \%(\mathrm{M} / \mathrm{V})$ skimmed milk powder with TBST $(0.05 \%$ Tween 20$)$ buffer was used for standby. After the transfer, the PVDF membrane was removed, immersed in TBST in the shaker at speed of $100 \mathrm{rpm}$ for $5 \mathrm{~min}$ at $25^{\circ} \mathrm{C}$. Then, TBST buffer was removed and the PVDF
Table I. Expression of long non-coding RNA maternally expressed 3 in OSCC tissues and cells.

\begin{tabular}{lccc}
\hline Group & Tissues $(\mathrm{n}=5)$ & SCC25 $(\mathrm{n}=5)$ & CAL27 $(\mathrm{n}=5)$ \\
\hline Normal & $3.45 \pm 0.12$ & $5.81 \pm 0.03$ & $4.73 \pm 0.03$ \\
OSCC & $1.66 \pm 0.16^{\mathrm{a}}$ & $1.04 \pm 0.11^{\mathrm{a}}$ & $1.58 \pm 0.12$ \\
Q-statistic & 27.853 & 106.259 & 74.5543 \\
P-value & 0.001 & 0.001 & 0.001 \\
\hline
\end{tabular}

${ }^{\mathrm{a}} \mathrm{P}<0.05$ vs. normal tissues or cells. IncRNA, long non-coding RNA; OSCC, oral squamous cell carcinoma.

membrane was immersed in skimmed milk powder solution in the shaker at speed of $100 \mathrm{r} / \mathrm{min}$ for $1 \mathrm{~h}$. The transferred proteins were probed with respective primary antibodies against b-actin (1:1,000; cat. no. WL01845, Wanleibio Co., Ltd.) and P53 (1:500, cat. no. WL01333, Wanleibio Co., Ltd.) overnight at $4^{\circ} \mathrm{C}$. After the membrane was washed with TBST buffer, the horseradish peroxidase-labeled secondary antibody (1:5,000, cat. no. WLA023, Wanleibio Co., Ltd.) was diluted with $5 \%$ skimmed milk powder/TBST solution to the relevant concentration. Then, the membrane was added into the second antibody solution, and the signals were developed using an enhanced chemiluminescent kit (cat. no. WLA003, Wanleibio Co., Ltd.) and was prepared for color development. The images were collected, exposed and the captured using Gel-Pro Analyzer 4.0 (Media Cybernetics, Inc.) system (39).

Statistical analysis. SPSS 22.0 software (IBM Corp.) was used for statistical analysis. The measurement data was expressed as mean $\pm \mathrm{SD}$. The measurement data was normally distributed, and the square difference was the same. The significance of the average values was analyzed using one-way ANOVA with a Tukey's HSD post hoc test. $\chi^{2}$-test and Fisher's Exact test were performed to analyze the count data. $\mathrm{P}<0.05$ was considered to indicate a statistically significant difference.

\section{Results}

lncRNA MEG3 expression in OSCC tissues and cells. RT-qPCR was employed to detect the relative expression of lncRNA MEG3 in OSCC tissues and corresponding normal tissues. The results showed that the expression of MEG3 in the OSCC tissues was significantly lower than that in the normal tissues $(\mathrm{P}<0.05)$. Compared with normal oral mucosa cells, the expression of lncRNA MEG3 in SCC25 and CAL27 cells was significantly lower $(\mathrm{P}<0.05$; Table I and Fig. 1A).

Construction of IncRNA MEG3 overexpression plasmid vector. Compared with the blank control group $(0.75 \pm 0.56)$ and empty vector group $(0.77 \pm 0.65)$, the relative expression level of lncRNA MEG3 mRNA in the overexpression group $(9.87 \pm 0.87)$ was significantly increased $(\mathrm{P}<0.05$; Fig. 1B).

lncRNA MEG3 expression level is significantly associated with clinicopathological features in patients with OSCC. According to the median value of IncRNA MEG3 expression 

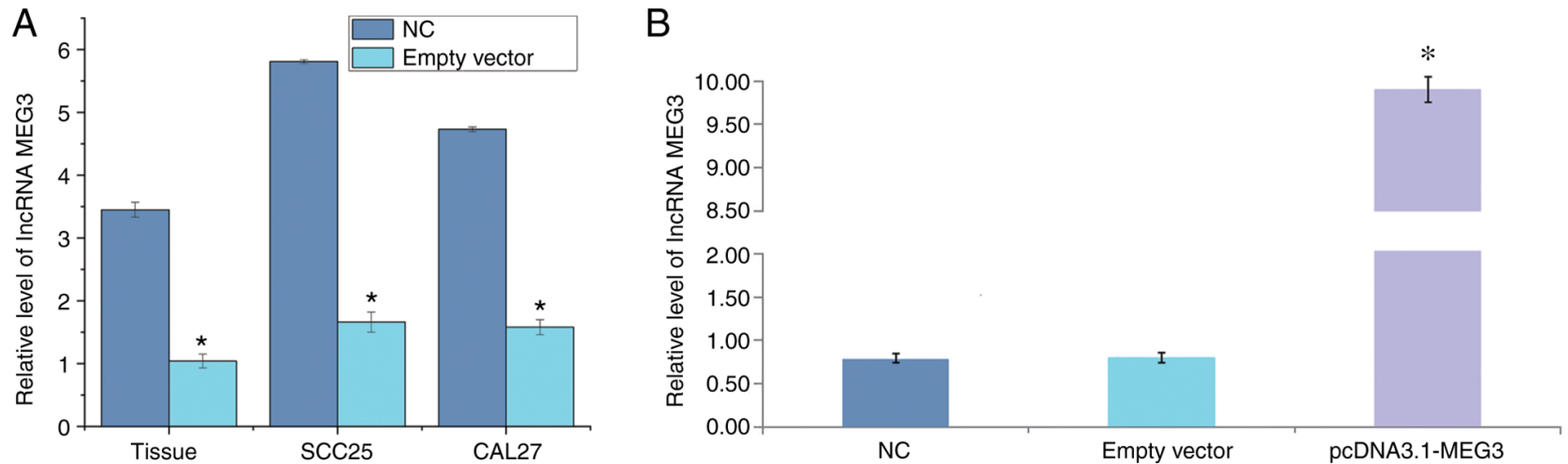

Figure 1. Expression level of lncRNA MEG3 detected by reverse transcription-quantitative PCR. (A) lncRNA MEG3 expression in oral squamous cell carcinoma tissues and cells. "P<0.05 vs. Normal group. (B) The differential expression of lncRNA MEG3 in pcDNA3.1-MEG3 group. "P<0.05 vs. NC and empty vector groups. lncRNA, long non-coding RNA; MEG3, maternally expressed 3; NC, negative control.
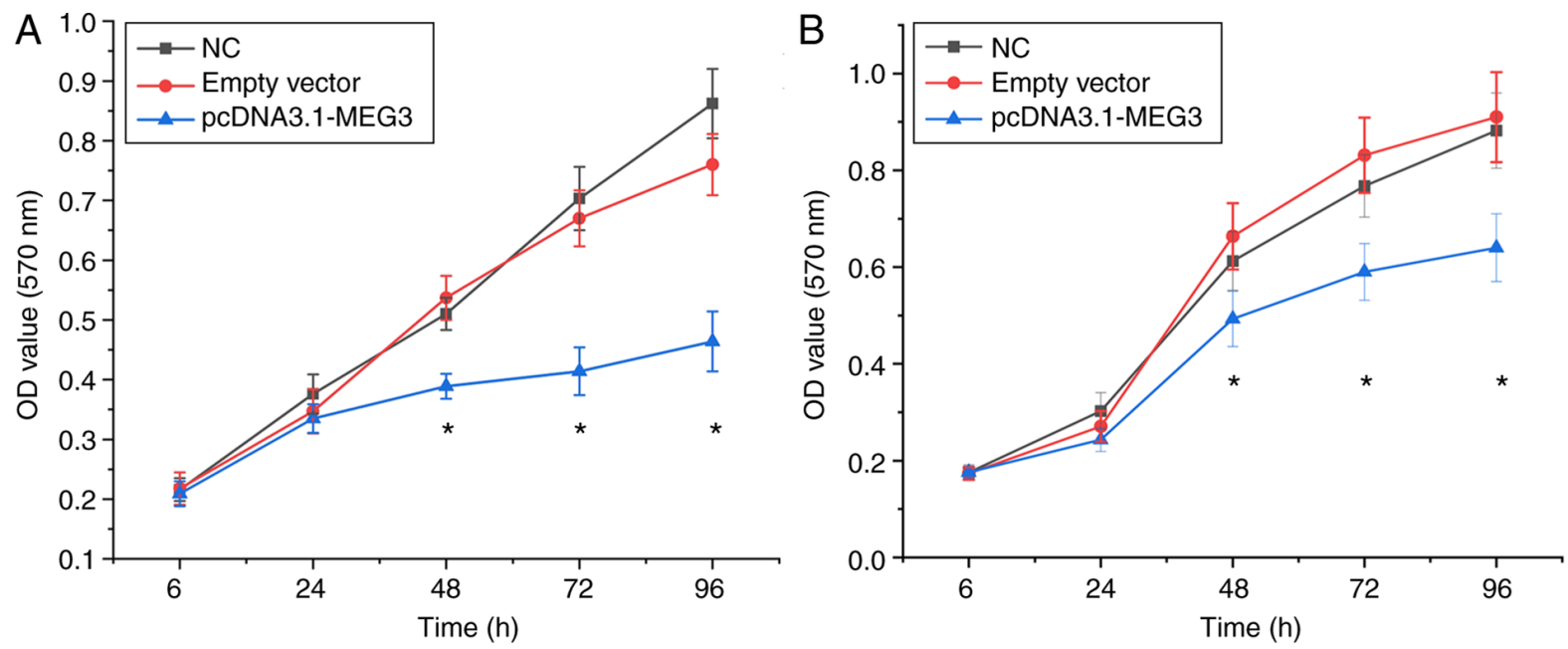

Figure 2. Inhibitory activity of pcDNA3.1-MEG3 against oral squamous cell carcinoma cells in different culture periods. (A) Inhibitory activity of pcDNA3.1-MEG3 against SCC25 cells in different culture periods. (B) Inhibitory activity of pcDNA3.1-MEG3 against CAL27 cells in different culture periods. ${ }^{~} \mathrm{P}<0.05$ vs. $\mathrm{NC}$ and empty vector group. MEG3, maternally expressed 3; NC, negative control.

level, patients with OSCC were divided into the high-(n=30) and low-expression $(n=42)$ groups. The associations between the expression of lncRNA MEG3 and patient age, sex, smoking status, tumor location, clinical stage, lymph node metastasis, distant metastasis and survival status were analyzed. The expression of IncRNA MEG3 was not associated with age, sex, smoking or tumor location $(\mathrm{P}>0.05)$, but was associated with clinical stage, lymph node metastasis, distant metastasis and survival status $(\mathrm{P}<0.05$; Table II).

Effect of IncRNA MEG3 on the proliferation of OSCC cells. After transfection for 6 and $24 \mathrm{~h}$, no significant difference was found in the cell proliferation of each group $(\mathrm{P}>0.05)$. After transfection for 48, 72 and $96 \mathrm{~h}$, the proliferation of the blank control and vector groups were significantly higher than that of the overexpression group $(\mathrm{P}<0.05)$. These results indicated that the overexpression of lncRNA MEG3 resulted in decreased proliferation of SCC25 and CAL27 cells (Fig. 2A and B).

Effect of IncRNA MEG3 on migration of OSCC cells. After overexpression of IncRNA MEG3 was established in the SCC25 and
CAL27 cells, the numbers of cells migrating and invading the membrane in the blank control and vector groups were significantly higher compared with the overexpression group $(\mathrm{P}<0.05)$.

In SCC 25 cells, the numbers of migrated and invaded cells in the blank control were $68.00 \pm 11.98$ and $48.60 \pm 6.39$, respectively. The numbers of cells migrated and invaded in the empty vector group were $63.60 \pm 7.83$ and $45.00 \pm 5.70$, respectively. In the IncRNA MEG3 group, the number migrated cells was 43.20 \pm 5.72 , and the number of invaded cells was $32.00 \pm 3.16$.

In CAL27 cells, the number of migrated and invaded cells in the blank control was $62.21 \pm 8.57$ and $54.00 \pm 5.39$, respectively. The number of migrated and invaded cells in the empty vector group was $58.60 \pm 8.73$ and $44.31 \pm 5.13$, respectively. In the IncRNA MEG3 group, the number of migrated cells was $33.20 \pm 7.21$, and the number of invaded cells was $29.00 \pm 2.86$. These results indicated that the overexpression of lncRNA MEG3 resulted in the decreased migration and invasion of SCC25 and CAL27 cells (Table III and Fig. 3).

Apoptosis of OSCC cells is induced by IncRNA MEG3. The apoptosis rates of SCC25 in the blank control, vector 
Table II. Association of long non-coding RNA maternally expressed 3 expression with clinicopathological characteristics of patients with oral squamous cell carcinoma.

\begin{tabular}{|c|c|c|c|c|c|}
\hline \multirow[b]{2}{*}{ Clinical characteristics } & \multirow[b]{2}{*}{ n-value } & \multicolumn{2}{|c|}{ MEG3 } & \multirow[b]{2}{*}{$c^{2}$-value } & \multirow[b]{2}{*}{ P-value } \\
\hline & & High (30) & Low (42) & & \\
\hline \multicolumn{6}{|l|}{ Age (years) } \\
\hline$<53$ & 32 & 15 & 17 & \multirow[t]{2}{*}{0.643} & \multirow[t]{2}{*}{0.515} \\
\hline$\geq 53$ & 40 & 15 & 25 & & \\
\hline \multicolumn{6}{|l|}{ Sex } \\
\hline Male & 35 & 16 & 19 & \multirow[t]{2}{*}{0.459} & \multirow[t]{2}{*}{0.853} \\
\hline Female & 37 & 14 & 23 & & \\
\hline \multicolumn{6}{|l|}{ Smoking } \\
\hline Yes & 42 & 20 & 22 & \multirow[t]{2}{*}{1.469} & \multirow[t]{2}{*}{0.361} \\
\hline No & 30 & 10 & 20 & & \\
\hline \multicolumn{6}{|l|}{ Tumor location } \\
\hline Tongue cancer & 30 & 12 & 18 & \multirow[t]{4}{*}{-} & 0.003 \\
\hline Gingival carcinoma & 22 & 9 & 13 & & 1.000 \\
\hline Carcinoma of the buccal mucosa & 10 & 5 & 5 & & 0.732 \\
\hline Others & 10 & 4 & 6 & & 1.000 \\
\hline \multicolumn{6}{|l|}{ Clinical stage } \\
\hline $\mathrm{T} 1$ & 28 & 18 & 10 & \multirow[t]{4}{*}{-} & 0.003 \\
\hline $\mathrm{T} 2$ & 25 & 6 & 19 & & 0.044 \\
\hline $\mathrm{T} 3$ & 15 & 5 & 10 & & 0.500 \\
\hline $\mathrm{T} 4$ & 4 & 1 & 3 & & 0.600 \\
\hline \multicolumn{6}{|l|}{ Lymphatic metastasis } \\
\hline Yes & 36 & 10 & 26 & \multirow[t]{2}{*}{4.629} & \multirow[t]{2}{*}{0.034} \\
\hline No & 36 & 20 & 16 & & \\
\hline \multicolumn{6}{|l|}{ Distant metastasis } \\
\hline Yes & 18 & 2 & 16 & \multirow[t]{2}{*}{9.219} & \multirow[t]{2}{*}{0.0028} \\
\hline No & 54 & 28 & 26 & & \\
\hline \multicolumn{6}{|l|}{ Survival status } \\
\hline Living & 49 & 27 & 22 & \multirow[t]{2}{*}{11.392} & \multirow[t]{2}{*}{0.002} \\
\hline Dead & 23 & 3 & 20 & & \\
\hline
\end{tabular}

and overexpression groups were $5.93 \pm 0.30,6.70 \pm 0.50$ and $11.7 \pm 0.71 \%$, respectively. Meanwhile, the apoptosis rates of CAL27 in the blank control, vector and overexpression groups were $5.52 \pm 0.37,6.50 \pm 0.44$ and $11.6 \pm 1.31 \%$, respectively. Compared with the blank control and vector groups, the apoptosis rate of the overexpression group was significantly increased $(\mathrm{P}<0.05)$, indicating that the overexpression of the lncRNA MEG3 may promote the apoptosis of SCC25 and CAL27 cells (Fig. 4).

Influence of IncRNA MEG3 on p53 expression. Western blot analysis was used to detect the expression of the $\mathrm{p} 53$ protein in the blank control group (1.04 \pm 0.056$)$, vector group $(1.09 \pm 0.35)$ and overexpression group $(2.66 \pm 0.012)$ in SCC25 cells. Meanwhile, the expression of p53 protein in the blank control group (1.94 \pm 0.33$)$, vector group $(1.78 \pm 0.017)$ and overexpression group (3.66 \pm 0.032$)$ in CAL27 cell was also detected. The results indicated that the overexpression of 1ncRNA MEG3 enhanced the expression of the p53 protein. RT-qPCR was
Table III. Number of migrated and invaded cells in each group.

\begin{tabular}{lcc}
\hline Cell line & Migrated cells, $\mathrm{n}$ & Invaded cells, $\mathrm{n}$ \\
\hline SCC25 & & \\
$\mathrm{NC}$ & $68.00 \pm 11.98$ & $48.60 \pm 6.39$ \\
Vehicle & $63.60 \pm 7.83$ & $45.00 \pm 5.70$ \\
pcDNA3.1-MEG3 & $43.20 \pm 5.72$ & $32.00 \pm 3.16$ \\
Q-statistic & 4.7592 & 4.4522 \\
P-value & 0.0143 & 0.0211 \\
CAL27 & & \\
NC & $62.21 \pm 8.57$ & $54.00 \pm 5.39$ \\
Vehicle & $58.60 \pm 8.73$ & $44.31 \pm 5.13$ \\
pcDNA3.1-MEG3 & $33.20 \pm 7.21$ & $29.00 \pm 2.86$ \\
Q-statistic & 6.1877 & 5.8146 \\
P-value & 0.0024 & 0.0038 \\
\hline
\end{tabular}

NC, negative control; MEG3, maternally expressed 3. 

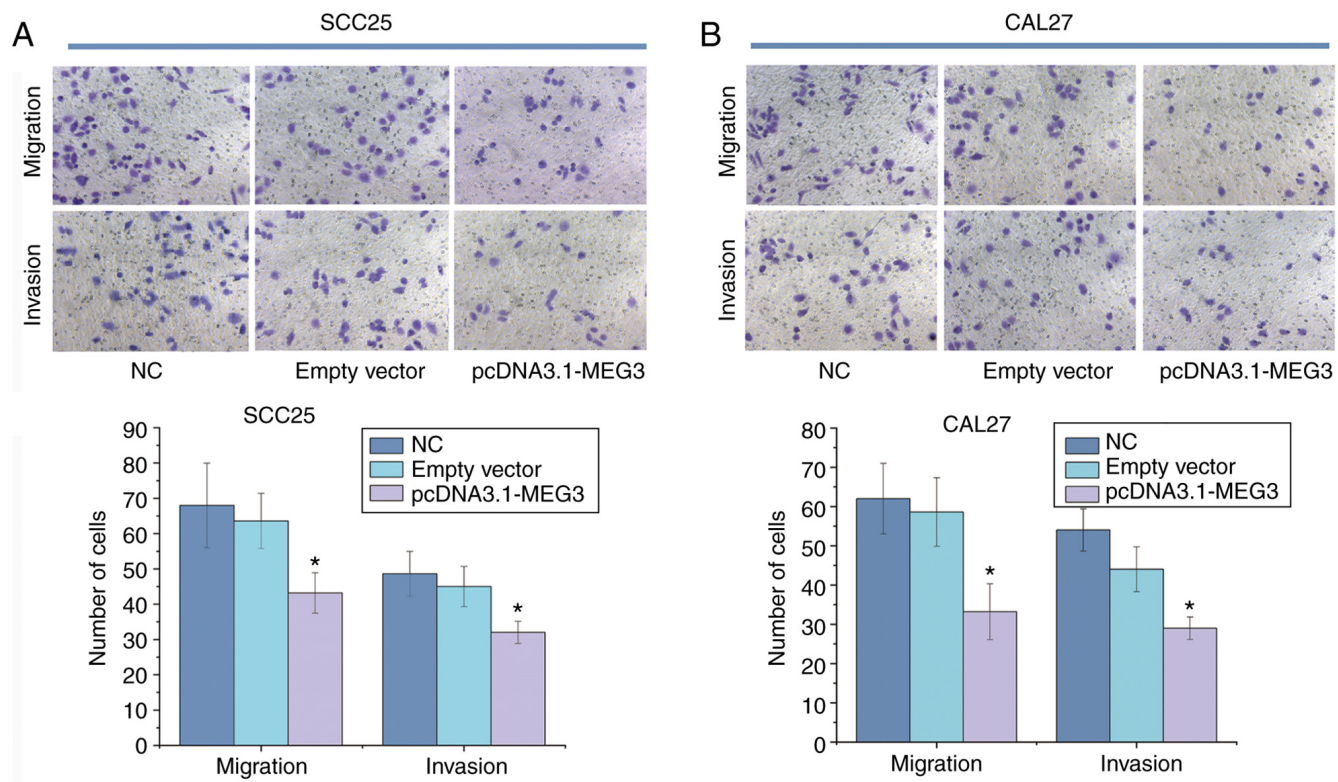

Figure 3. Transwell migration and invasion assays were used to determine the effect of overexpression of long non-coding RNA maternally expressed 3 on the motility of oral squamous cell carcinoma cells in vitro. (A) SCC25 cells; (B) CAL27 cells. " $\mathrm{P}<0.05$ vs. NC and empty vector group. NC, negative control.
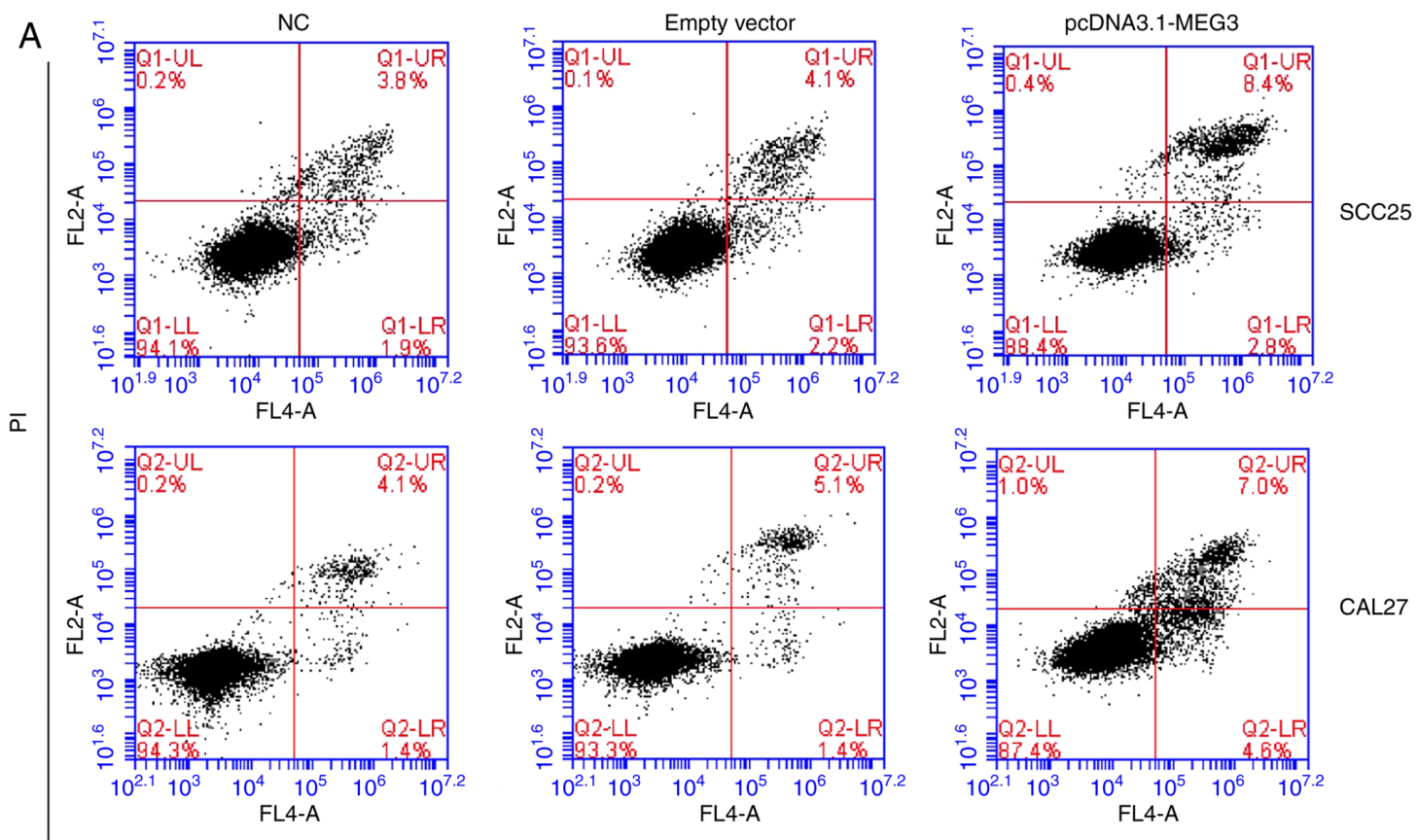

Annexin $\mathrm{V}$
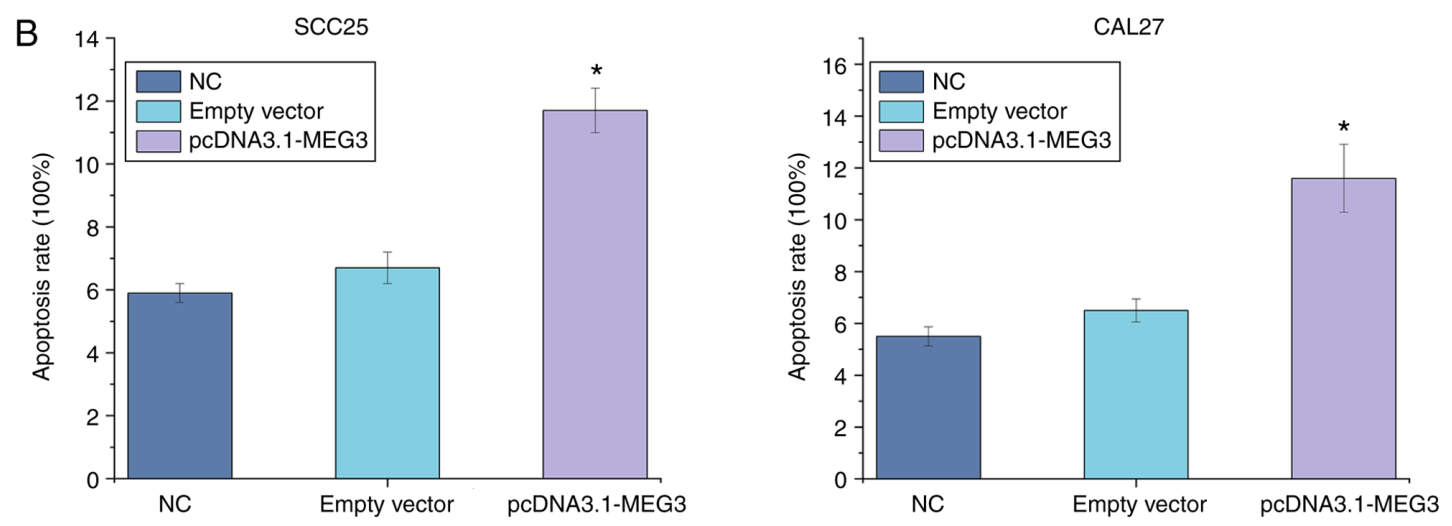

Figure 4. Flow cytometry was used to detect the effect of long non-coding RNA MEG3 on apoptosis of oral squamous cell carcinoma cells. (A) Results of flow cytometry. (B) Comparison of apoptosis rate of each group. " $\mathrm{P}<0.05$ vs. NC and empty vector group. NC, negative control; MEG3, maternally expressed 3. 
used to detect the expression of p53 mRNA in each group. Compared with the blank control group and vector group, the expression level of the p53 mRNA in the overexpression group was significantly increased $(\mathrm{P}<0.05)$. The overexpression of the IncRNA MEG3 resulted in promotion of the expression of the p53 signaling pathway (Fig. 5).

\section{Discussion}

lncRNA MEG3 serves the role of a tumor suppressor gene in malignant tumors, such as liver, gastric and bladder cancers (40). The loss-of-function or decreased expression of this transcript directly results in cancer. In the present study, expression levels in 72 OSCC tissue samples were detected. The results indicated that the expression of lncRNA MEG3 in the OSCC tissues was significantly lower than that in the corresponding normal tissues. This expression trend was consistent with that of other cancer types and was closely associated with the clinical stage, lymph node metastasis, distant metastasis and survival status of patients with OSCC. The results also suggested that the expression of lncRNA MEG3 was closely related to the clinical stage, lymph node metastasis, distant metastasis and survival status. To further explore the effects of 1ncRNA MEG3 in the OSCC cells, SCC25 and CAL27 cells were transfected using Lipofectamine 2000 to overexpress lncRNA MEG3 and observe changes in the biological behavior of SCC25 and CAL27 cells. With the use of MTT, Transwell chamber and flow cytometry assays, overexpression of lncRNA MEG3 was found to significantly inhibit the proliferation and invasion capacity of SCC25 and CAL27 cells and promote apoptosis. These results indicated that lncRNA MEG3 had a significant inhibitory effect on the OSCC cells. This phenomenon indicates that lncRNA MEG3 also serves an important role in OSCC.

LncRNA MEG3 can directly bind the p53 DNA domain, stimulate the activation of p53-mediated association and promote the apoptosis of cancer cells $(36,41,42)$. Therefore, IncRNA MEG3 may also inhibit cell activity and induce apoptosis by promoting p53 gene expression in OSCC. Moreover, the expression level of the p53 gene was detected. The results showed that following overexpression of lncRNA MEG3, the expression of p53 increased significantly in SCC25 cells. This result suggested that lncRNA MEG3 may represent an upstream regulator of p53 activation, which is consistent with the results obtained by Zhang et al (43). Therefore, the upregulation of lncRNA MEG3 expression and activation of p53 pathway may have therapeutic potential when used to inhibit the proliferation and invasion of OSCC cells.

The abnormal expression of 1ncRNA MEG3 (such as upregulation or downregulation) may result in the development primary malignant tumors, which may be due to the methylation or hypermethylation of a gene promoter $(44,45)$. Epigenetic silencing of tumor suppressor genes is associated with the hypermethylation of the promoter CpG island (CGI), which can be considered an early warning of cancer. The MEG3 promoter region contains numerous CGIs and has two different methylation regions (DMR), namely, IG-DMR and MEG3-DMR, which are located upstream of the MEG3 gene, which is the imprinting control center of the DLK1-MEG3 locus $(46,47)$. A previous study demonstrated that the

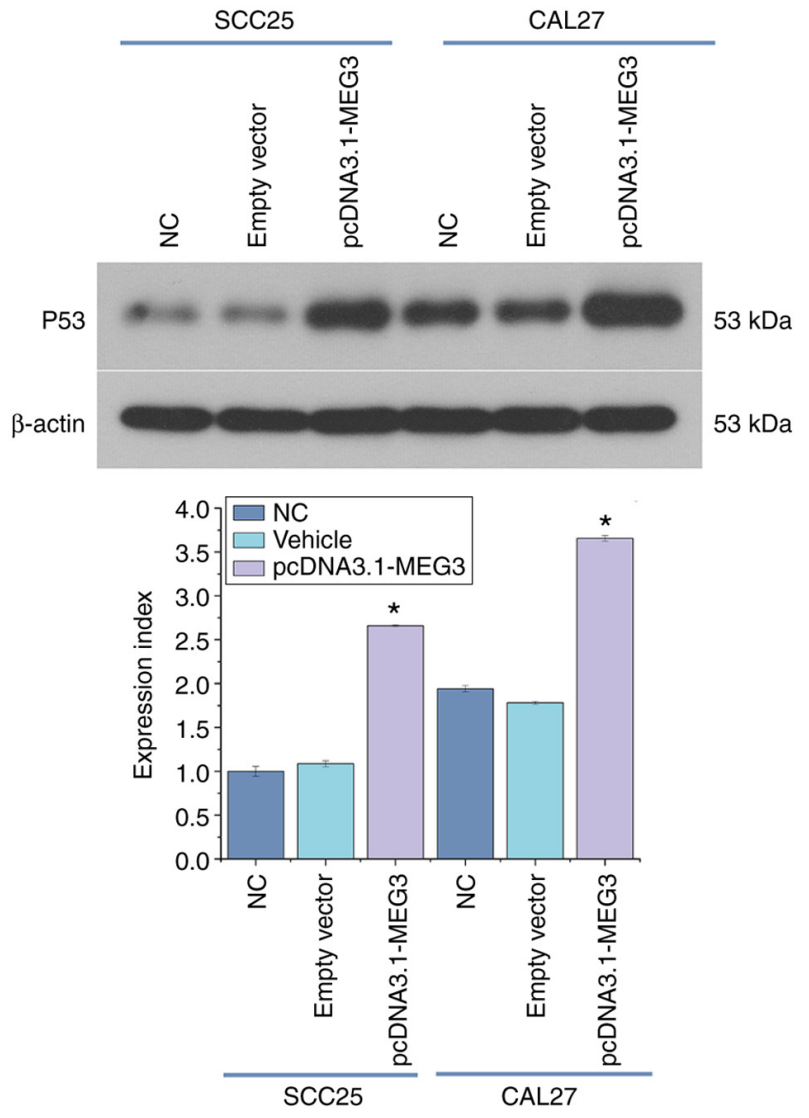

Figure 5. Effect of 1ncRNA MEG3 on the expression of p53 protein in oral squamous cell carcinoma cells. ${ }^{*} \mathrm{P}<0.05$ vs. NC and empty vector groups. NC, negative control; MEG3, maternally expressed 3.

methylation of MEG3 promoter in patients with esophageal squamous cell carcinoma directly led to the inhibition of MEG3 expression, resulting in the inhibition of tumor cell apoptosis (48). The aforementioned studies demonstrated that the abnormal methylation of the MEG3 promoter may promote the progress of malignant tumors, thus inhibiting the formation and occurrence of methylation and promoting the expression of tumor suppressor genes. These mechanisms are expected to represent novel targets for tumor treatment.

In conclusion, the present study confirmed that lncRNA MEG3 inhibits the proliferation, migration and invasion capacities of SCC25 and CAL27 cells by targeting p53 and promoting apoptosis. A theoretical basis and experimental data for potential prevention and treatment of OSCC with lncRNA MEG3 as a target have been identifies. However, other targeted pathways besides the regulatory mechanism of MEG3-p53 have not been fully elucidated and need to be further studied. In the later stages, in addition to silencing lncRNA MEG3 to further confirm its effect on the OSCC cell function, its inhibitory effect on tumor growth in an in vivo model should also be analyzed. The potential target genes and signaling pathways of lncRNA MEG3 need to be explored further to provide additional experimental basis for the early application of lncRNA MEG3 as a molecular target for clinical tumor therapy.

\section{Acknowledgements}

Not applicable. 


\section{Funding}

The present study was funded by Hebei Key Project Plan of Medical Science Research (grant no. 20210213).

\section{Availability of data and materials}

The datasets used and/or analyzed during the current study are available from the corresponding author on reasonable request.

\section{Authors' contributions}

WW and TL designed the study, and performed the experiments alongside HL. WW wrote the manuscript and analyzed the data alongside YQ. KL helped with the investigation and formal analysis of data. YL and QD contributed to the methodology and data analysis. All authors read and approved the final version of the manuscript. KL, YL and QD confirmed the authenticity of all the raw data.

\section{Ethics approval and consent to participate}

The Ethics Committee of the Fourth Affiliated Hospital (Shijiazhuang, China) approved the experiment and supervised and guided the whole experimental process (approval no. 201411EC040). All patients provided written informed consent.

\section{Patient consent for publication}

Not applicable.

\section{Competing interests}

The authors declare that they have no competing interests.

\section{References}

1. Yang B, Dong K, Guo P, Guo P, Jie G, Zhang G and Li T: Identification of key biomarkers and potential molecular mechanisms in oral squamous cell carcinoma by bioinformatics analysis. J Comput Biol 27: 40-54, 2020.

2. Kademani D: Oral cancer. Mayo Clin Proc 82: 878-887, 2007.

3. Joseph JP, Harishankar MK, Pillai AA and Devi A: Hypoxia induced EMT: A review on the mechanism of tumor progression and metastasis in OSCC. Oral Oncol 80: 23-32, 2018.

4. Kim SY, Han YK, Song JM, Lee CH, Kang K, Yi JM and Park HR: Aberrantly hypermethylated tumor suppressor genes were identified in oral squamous cell carcinoma (OSCC). Clin Epigenetics 11: 116, 2019.

5. Chong CE, Lim KP, Gan CP, Marsh CA, Zain RB, Abraham MT, Prime SS, Teo SH, Silvio Gutkind J, Patel V and Cheong SC: Over-expression of MAGED4B increases cell migration and growth in oral squamous cell carcinoma and is associated with poor disease outcome. Cancer Lett 321: 18-26, 2012.

6. Sun C and Li J: Expression of MiRNA-137 in oral squamous cell carcinoma and its clinical significance. J BUON 23: 167-172, 2018

7. Qiu YL, Liu YH, Ban JD, Wang WJ, Han M, Kong P and Li BH: Pathway analysis of a genome-wide association study on a long non-coding RNA expression profile in oral squamous cell carcinoma. Oncol Rep 41: 895-907, 2019.

8. Jin T, Guo Y, Huang Z, Zhang Q, Huang Z, Zhang Y and Huang Z: Vitamin D inhibits the proliferation of oral squamous cell carcinoma by suppressing lncRNA LUCAT1 through the MAPK pathway. J Cancer 11: 5971-5981, 2020.

9. Wang X, Yang S, Lv X, Wang L and Li C: Overexpression of LncRNA SNHG1 were suitable for oncolytic adenoviruse H101 therapy in oral squamous-cell carcinoma. OncoTargets Ther 13: $13033-13039,2020$.
10. Gullerova M: Long non-coding RNA. In: Genomic Elements in Health, Disease and Evolution. Felekkis K and Voskarides K (eds). Springer, New York, NY, pp83-108, 2015.

11. Cui HB, Ge HE, Wang YS and Bai XY: MiR-208a enhances cell proliferation and invasion of gastric cancer by targeting SFRP1 and negatively regulating MEG3. Int J Biochem Cell Biol 102: 31-39, 2018

12. Bayarmaa B, Wu Z, Peng J, Wang Y, Xu S, Yan T, Yin W, Lu J and Zhou L: Association of LncRNA MEG3 polymorphisms with efficacy of neoadjuvant chemotherapy in breast cancer. BMC Cancer 19: 877, 2019.

13. Zhang J, Yao T, Wang Y, Yu J, Liu Y and Lin Z: Long noncoding RNA MEG3 is downregulated in cervical cancer and affects cell proliferation and apoptosis by regulating miR-21. Cancer Biol Ther 17: 104-113, 2016.

14. Dykes IM and Emanueli C: Transcriptional and post-transcriptional gene regulation by long non-coding RNA. Genom Proteom Bioinf 15: 177-186, 2017.

15. Vafadar A, Shabaninejad Z, Movahedpour A, Mohammadi S, Fathullahzadeh S, Mirzaei HR, Namdar A, Savardashtaki A and Mirzaei H: Long non-coding RNAs as epigenetic regulators in cancer. Curr Pharm Design 25: 3563-3577, 2019.

16. Huarte M: The emerging role of LncRNAs in cancer. Nat Med 21: 1253-1261, 2015.

17. Qiu C, Li S, Sun D and Yang S: lncRNA PVT1 accelerates progression of non-small cell lung cancer via targeting miRNA 526b/EZH2 regulatory loop. Oncol Lett 19: 1267-1272, 2020.

18. Han X, Zheng J, Wang Y and Gao Z: MiRNA 29a inhibits colon cancer growth by regulation of the PTEN/Akt/GSK3 $\beta$ and Wnt $/ \beta$ catenin signaling pathways. Oncol Lett 16: 2638-2644, 2018.

19. Zheng Z, Li W, Xu J, Xie B, Yang M, Huang H, Li H and Wang Q: LncMSEN1, a mantle specific LncRNA participating in nacre formation and response to polyI: $\mathrm{C}$ stimulation in pearl oyster Pinctada fucata martensii. Fish Shellfish Immunol 96: 330-335, 2020.

20. Liu S, Wu L, Qi H and Xu M: LncRNA/circRNA-miRNA-mRNA networks regulate the development of root and shoot meristems of Populus. Ind Crop Prod 133: 333-347, 2019.

21. Gibb EA, Vucic EA, Enfield KS, Stewart GL, Lonergan KM, Kennett JY, Becker-Santos DD, MacAulay CE, Lam S, Brown CJ and Lam WL: Human cancer long non-coding RNA transcriptomes. PLoS One 6: e25915, 2011.

22. He Q, Long J, Yin Y, Li Y, Lei X, Li Z and Zhu W: Emerging roles of lncRNAs in the formation and progression of colorectal cancer. Front Oncol 9: 1542, 2020.

23. Guo QY, Wang H and Wang Y: LncRNA H19 polymorphisms associated with the risk of OSCC in Chinese population. Eur Rev Med Pharmacol Sci 21: 3770-3774, 2017.

24. Liu L, Zhan Y, Huang Y and Huang L: LncRNA FGD5-AS1 can be predicted as therapeutic target in oral cancer. J Oral Pathol Med 49: 243-252, 2020.

25. Sun CC, Zhang L, Li G, Li SJ, Chen ZL, Fu YF, Gong FY, Bai T, Zhang DY, Wu QM and Li DJ: The lncRNA PDIA3P interacts with miR-185-5p to modulate oral squamous cell carcinoma progression by targeting cyclin D2. Mol Ther Nucleic Acids 9: 100-110, 2017.

26. Niu X, Yang B, Liu F and Fang Q: LncRNA HOXA11-AS promotes OSCC progression by sponging miR-98-5p to upregulate YBX2 expression. Biomed Pharmacother 121: 109623, 2020.

27. Wang X, Li H and Shi J: LncRNA HOXA11-AS promotes proliferation and cisplatin resistance of oral squamous cell carcinoma by suppression of miR-214-3p expression. Biomed Res Int 2019: 8645153, 2019.

28. Zhou Y, Zhang X and Klibanski A: MEG3 noncoding RNA: A tumor suppressor. J Mol Endocrinol 48: R45-R53, 2012.

29. Zhang J, Liang Y, Huang X, Guo X, Liu Y, Zhong J and Yuan J: STAT3-induced upregulation of IncRNA MEG3 regulates the growth of cardiac hypertrophy through miR-361-5p/HDAC9 axis. Sci Rep 9: 460, 2019.

30. Schuster-Gossler K, Bilinski P, Sado T, Ferguson-Smith A and Gossler A: The mouse GTL2 gene is differentially expressed during embryonic development, encodes multiple alternatively spliced transcripts, and may act as an RNA. Dev Dyn 212: 214-228, 1998.

31. Takahashi N, Okamoto A, Kobayashi R, Shirai M, Obata Y, Ogawa H, Sotomaru Y and Kono T: Deletion of GTL2, imprinted non-coding RNA, with its differentially methylated region induces lethal parent-origin-dependent defects in mice. Hum Mol Genet 18: 1879-1888, 2009. 
32. Zhou Y, Cheunsuchon P, Nakayama Y, Lawlor MW, Zhong Y, Rice KA, Zhang L, Zhang X, Gordon FE, Lidov HG, et al: Activation of paternally expressed genes and perinatal death caused by deletion of the GTL2 gene. Development 137: 2643-2652, 2010.

33. Stadtfeld M, Apostolou E, Akutsu H, Fukuda A, Follett P, Natesan S, Kono T, Shioda T and Hochedlinger K: Aberrant silencing of imprinted genes on chromosome $12 \mathrm{qF} 1$ in mouse induced pluripotent stem cells. Nature 465: 175-181, 2010.

34. Kaneko S, Bonasio R, Saldaña-Meyer R, Yoshida T, Son J, Nishino K, Umezawa A and Reinberg D: Interactions between JARID2 and noncoding RNAs regulate PRC2 recruitment to chromatin. Mol Cell 53: 290-300, 2014

35. Wei GH and Wang X: lncRNA MEG3 inhibit proliferation and metastasis of gastric cancer via p53 signaling pathway. Eur Rev Med Pharmacol Sci 21: 3850-3856, 2017.

36. Hu D, Su C, Jiang M, Shen Y, Shi A, Zhao F, Chen R, Shen Z, Bao J and Tang W: Fenofibrate inhibited pancreatic cancer cells proliferation via activation of $\mathrm{p} 53$ mediated by upregulation of LncRNA MEG3. Biochem Biophys Res Commun 471: 290-295, 2016.

37. Livak KJ and Schmittgen TD: Analysis of relative gene expression data using real-time quantitative PCR and the 2(-Delta Delta C(T)) method. Methods 25: 402-408, 2001.

38. Zhao Y and Hong L: lncRNA-PRLB confers paclitaxel resistance of ovarian cancer cells by regulating RSF1/NF- $\kappa \mathrm{B}$ signaling pathway. Cancer Biother Radiopharm 36: 202-210, 2021.

39. Zhao H, Zheng GH, Li GC, Xin L, Wang YS, Chen Y and Zheng XM: Long noncoding RNA LINC00958 regulates cell sensitivity to radiotherapy through RRM2 by binding to microRNA-5095 in cervical cancer. J Cell Physiol 234 23349-23359, 2019.

40. Al-Rugeebah A, Alanazi M and Parine NR: MEG3: An oncogenic long non-coding RNA in different cancers. Pathol Oncol Res 25: 859-874, 2019.

41. Li X, Zhao J, Geng J, Chen F, Wei Z, Liu C, Zhang X, Li Q, Zhang J, Gao L, et al: Long Non-Coding RNA MEG3 knockdown attenuates endoplasmic reticulum stress-mediated apoptosis by targeting p53 following myocardial infarction. J Cell Mol Med 23: 8369-8380, 2019.
42. Uroda T, Anastasakou E, Rossi A, Teulon JM, Pellequer JL, Annibale P, Pessey O, Inga A, Chillón I and Marcia M: Conserved pseudoknots in lncRNA MEG3 are essential for stimulation of the p53 pathway. Mol Cell 75: 982-995.e9, 2019.

43. Zhang LL, Hu D and Zou LH: Low expression of lncRNA MEG3 promotes the progression of oral squamous cell carcinoma by targeting miR-21. Eur Rev Med Pharmacol Sci 22: 8315-8323, 2018.

44. Dong Z, Zhang A, Liu S, Lu F, Guo Y, Zhang G, Xu F, Shi Y, Shen S, Liang J and Guo W: Aberrant methylation-mediated silencing of lncRNA MEG3 functions as a ceRNA in esophageal cancer. Mol Cancer Res 15: 800-810, 2017.

45. Molina-Pinelo S, Salinas A, Moreno-Mata N, Ferrer I, Suarez R, Andrés-León E, Rodríguez-Paredes M, Gutekunst J, Jantus-Lewintre E, Camps C, et al: Impact of DLK1-DIO3 imprinted cluster hypomethylation in smoker patients with lung cancer. Oncotarget 9: 4395-4410, 2018.

46. Hill KE, Kelly AD, Kuijjer ML, Barry W, Rattani A, Garbutt CC, Kissick H, Janeway K, Perez-Atayde A, Goldsmith J, et al: An imprinted non-coding genomic cluster at $14 \mathrm{q} 32$ defines clinically relevant molecular subtypes in osteosarcoma across multiple independent datasets. J Hematol Oncol 10: 107, 2017.

47. Zhang J, Lin Z, Gao Y and Yao T: Downregulation of long noncoding RNA MEG3 is associated with poor prognosis and promoter hypermethylation in cervical cancer. J Exp Clin Cancer Res 36: 5, 2017.

48. Gao Y, Huang P and Zhang J: Hypermethylation of MEG3 promoter correlates with inactivation of MEG3 and poor prognosis in patients with retinoblastoma. J Transl Med 15: 268, 2017.

(i) $\Theta$ This work is licensed under a Creative Commons Attribution-NonCommercial-NoDerivatives 4.0 International (CC BY-NC-ND 4.0) License. 